\title{
A Comparative Analysis of Reliability Indices of Kaduna and Kano Distribution Systems
}

\author{
GaniyuAdedayoAjenikoko Moshood Kola Omotosho \\ Department of Electronic and Electrical Engineering, LadokeAkintola University of Technology, \\ P.M.B. 4000, Ogbomoso, Nigeria
}

\begin{abstract}
Reliability indices such as System Average Interruption Duration Index (SAIDI), System Average Interruption Frequency Index (SAIFI) and Customer Average Interruption Duration Index (CAIDI) are so significant in assessing the reliability levels of power systems.A comparative analysis of reliability indices of Kaduna and Kano distribution systems was carried out. Ten years of outage data information from ten selected distribution feeders of Kaduna and Kano distribution systems were used in this paper. The mean and standard deviation of the basic reliability indices were computed using appropriate mathematical relations as input parameters. The variances of these parametric indicators were also computed.FDR3 feeder of Kaduna distribution system recorded the highest mean SAIDI of 0.1064 compared to all other feeders in the selected distribution system. Customers on this feeder were interrupted for a prolonged time while fewer of the customers were adequately served. Junction Road feeder of Kaduna distribution system had the least mean SAIDI of 0.0704 because customers' interruption was for a short period of time even though; more customers were being served by the feeder.Bangauda feeder of Kano distribution system recorded the highest mean SAIDI of 0.1462. More customers were interrupted compared to all other feeders in the distribution system while fewer of them were adequately served while Spare feeder had a least mean SAIDI of 0.0497 because fewer of the customers attached to this feeder were interrupted while many of them were adequately served.The result of this research paper will provide a comparative analysis of the reliability indices of the selected distribution feeders on Kaduna and Kano distribution systems which will go a long way providing background information for distribution system engineers for adequate planning and maintenance of distribution feeders.
\end{abstract}

Keywords: SAIDI, SAIFI, CAIDI, Customers' interruptions, Power systems, Reliability indices, Distribution systems.

DOI: $10.7176 / \mathrm{JETP} / 9-8-05$

Publication date: November $30^{\text {th }} 2019$

\subsection{Introduction}

For reliability evaluation purposes, the continuously operating reliability indices in distribution systems are generally classified into two categories: repairable and non-repairable. For repairable system, if a component of a system fails, it is repaired and the system is put back into operation. However a non-repairable system dies when it fails and it needs to be replaced by a new one.

Power system falls in the category of a repairable system, and some indices are used to access the reliability levels. Reliability indices are considered to be logical ways of judging the performance of an electrical power system. Power systems have three main components: generation, transmission and distribution systems. The generation system produces electricity; transmission system delivers the generated electricity to distribution systems for supplying load demands. Both the generation and transmission systems are called the composite system or the bulk power system (Billinton, 2004, Singh and Billinton, 2005). Power quality is very important to certain customers. For this reason, many utilities could sell electrical energy at different prices to their customers, depending on the quality of the delivered electric power. Since most end users are connected to secondary distribution networks, at low voltage, it could be important to monitor and compensate the main disturbances on the low voltage grid (Khan and Billinton, 2002).

In power systems, effective reliability analysis is an essential factor in long term and operational planning. Accurate reliability analysis of power system helps to predict future failure behavior and make appropriate maintenance plans. Distributed generation (DG) is defined by the Electric Power Research Institute (EPRI) as a small scale $(0.50 \mathrm{MW})$ energy resource connected directly to the distribution network. Distributed generation has the advantage that, as the population expands and power generation needs change, the transmission network does not require expensive upgrades and extensions, as the generation source can be efficiently taken to the load in a more efficient manner (Mahmud and Saeed,2009). Distribution networks are normally meshed in design but the operation is nearly always configured radially. Re-configuration consists of changing the network configuration by opening/closing feeders and tie switches so that the networks become radial in operation. The configuration of distribution networks may be modified manually or by automatic switching operations for supplying the loads aiming at minimizing the cost of active power losses. Likewise, reconfiguration may increase system security and power quality (Arild and Arne, 2006). 
A number of power system equipment, such as generators, transmission/distribution lines, or transformers has been increasingly growing old around the world. Maintenance policies play an important role in the reliability of repairable systems because maintenance actions can significantly affect the failure probability of the system. For a complex system, i.e. a unit with a large number of parts, the repair or the substitution of a failed part restores the system performance, but does not generally produce a significant reliability improvement because the conditions of the non-failed parts are left unchanged. In such a case, it is generally assumed that each repair brings the system to condition it was just before failure occurrence (Billinton and Singh, 2004).

Reliability performance of distribution utilities has received considerable attention in recent years (Billinton and Wang,2016).The reliability of power distribution systems is greatly affected by outages caused by different environmental factors on overhead lines. Since animals cause significant number of outages on overhead distribution systems, it is important to investigate these outages (Danny,2015).

The main objective of restructuring is to introduce competition in the power industry and to reduce electricity cost to customers. In conventional power systems, electricity prices and system reliabilities are centrally controlled and managed by the system operators. Electricity prices are usually determined by the administration and are fixed for the same type of customers at different locations. In the new deregulated environment, electricity prices vary with time and location which are determined by the power market structures, generation buildings, customer demands, locations and choice on price and reliability (El-Kady et al,2007).

\subsection{Related Works.}

In power system reliability evaluation, failure and repair state of a component are modeled as an alternative renewal process. If only up times are considered, they are typically modeled by a renewal process in which the inter- arrival times are considered independently and identically distributed.

Most of the models in power system further assume that these up times are distributed exponentially leading to a homogenous poisson process(HPP). The function of an electric power system is to satisfy the system load requirement with a reasonable assurance of continuity and quality. The ability of the system to provide an adequate supply of electrical energy is usually designated by the term 'reliability' (Enrico and Gianfranco,2004, Faraget al., 2008,Khan, 2008, Khan and Billinton,2012). The concept of power system reliability is extremely broad and covers all aspects of the ability of the system to satisfy the customers' requirements. Adequacy assessment relates to the ability of the system to supply electric energy requirements of customers in a satisfactory manner. Since adequacy assessment deals with static condition, it does not include the evaluation of the system response to transient disturbances. Security assessment deals with the ability of the electric system to survive sudden disturbances such as electric short circuits or unanticipated loss of system elements. This includes the response of the system continuously to the loss of generation and transmission lines (Khodret al.,2017, Mahmud and Saeed, 2009).

A wide range of probabilistic techniques have been developed. These include techniques for reliability evaluation, probability load flow and probabilistic transient stability. The fundamental and common concept behind each of these techniques is the need to recognize that power system behaves stochastically and all input, output state and event parameters are probabilistic variables. Probabilistic techniques, which recognize not only the severity of state of an event and its impact on a system behavior and operation but also the likelihood of its occurrence, have been developed (Merysam and Hasan,2009, Mitra and Singh 2006,Nagaraj et al., 2014)..

Generally, there is no unique methodology to model the load Probability Density Function (PDF).The Gaussian modeling of the load appears to be a natural choice for various application due to its simplicity as it can be completely described by two moments (mean and variance). Although there are a host of two parameter distribution, the Gaussian is preferable because the analysis based on this distribution is well developed and many computational tools such as the state estimation function can easily incorporate the Gaussian probability density function.

\subsection{Reliability Centered Maintenance}

Reliability Centered Maintenance (RCM). RCM is a unique programative approach to predictive maintenance targeting just maintenance intervention to avoid failures and optimize costs. Maintenance management is an important drive for achieving increased power reliability. Maintenance management includes all work performed to keep physical distribution assets in operating conditions. It include preventive, predictive and maintenance management which ensures the productivity of the utility by influencing the percentage of time that its physical assets are available to operate. This directly affects the financial and service performance of the Company (Noferi and Paris 2014; Roberts et al,2008, Sacket et al, 2007).

\subsection{Review of Previous Studies}

Sakis et al, 2014 proposed a cost reliability index for evaluating distribution system design. A cost effectiveness ratio loss was suggested by him as a useful indicator for selecting a preferred design. The effect of automatic 
protective or sectionalizing devices on cost reliability indices was analyzed and the results presented graphically for convenient application. Mahmud and Saeed (2009) presented reliability analysis in electrical distribution system considering preventive maintenance applications on circuit breakers. The paper presents the results of the preventive maintenance application based study and modeling of failure rates in breakers of electrical distribution system which is a critical issue in the reliability assessment of a system. In the analysis considered in this paper, the impacts of failure rate variations caused by a preventive maintenance are examined. This is considered as part of a Reliabilty Centred Maintenance (RCM) application program. A number of load point reliability indices is derived using the mathematical model of the failure rate which is established using the observed data in a distribution system.

Awosope (1984) presented the impact which any criterion imposed on reliability measurement may have on electricity utility and meeting the societal expectations. The possible interactions between such criterion and cost benefit aspects of reliability are fully identified. All available techniques of handling this delicate issue of directly costing reliability are also discussed and are fully compared. Billinton (2004) illustrated a probabilistic technique to assess the operating reserve requirements in a system. In this approach, the generation system is classified into different system operating states. This technique combines deterministic criteria with probabilistic indices to monitor the system well-being, as designated by deterministic criteria.

Faraget al (2008) developed a new probabilistic reliability assessment framework and economic models for reliability planning. A Markov model of the new reliability framework, which is expected to provide a major advancement in the field, is also presented.

Mitra and Singh (2006) incorporated DC load flow model in the decomposition simulation method for multiarea reliability evaluation. State enumeration approach using topological analysis has been used to evaluate bulk power system reliability. System frequency, duration and availability indices have been obtained using topological enumeration. The method requires the use of AC or DC load flow to test the condition of contingency state.

Nagaraj et al (2014) presented modeling and analysis of distribution reliability indices. In this paper, an efficient Monte Carlo simulation method for distribution system reliability assessment is presented. Analysis of outage data from a practical distribution system is performed to determine the failure and repair models appropriate for use in the Monte Carlo simulation. The sensitivity of the reliability indices to the choice of model is presented. Finally, the impact of protection devices on the statistical distribution of SAIFI for a practical distribution feeder is presented.

Sakiset al (2006) described how aging characteristics can quantitatively influence reliability calculations in power systems and calculations of commonly used reliability indices such as loss of load expectations (LOLE). In order to construct the system failure and repair history of components, sequential Monte Carlo simulation method using stochastic point process modeling is introduced. Three methods are described for this paper and this methodology is applied to the Single Area IEEE Reliability Test System. The results are analyzed and compared.

Sakiset al, (2015) provided the results of a nationwide survey on the recording or measuring of data used to calculate reliability indices. It pointed out some of the pitfalls of using different methodologies in the recording of data. These differences often cause discrepancies when comparing reliability indices between utilities.

\subsection{METHODOLOGY}

\subsection{Background Analysis}

A variety of reliability indices for a distribution system exist. These indices can be divided into three categories, namely single load point indices, customer oriented indices and load oriented indices. Single load point indices provide service reliability data from an individual customer view point. System reliability is normally stated in terms of the average values of the relevant reliability indices. The expected value indicates the central tendency of a random variable and is the primary index of system adequacy in most system reliability indices.

\subsection{Method of collecting data for the analysis}

For the purpose of analyzing this work, the national control centre NCC osogbo was visited. The coverage period of the data collected is for a period of ten years. Information on the outage Data on Kaduna and Kano distribution system feeders were obtained to aid the analysis.

The data collected from NCC, Osogbo include:

Recorded faults on each of the selected distribution system from the study period.

Recorded outage times on each of the selected distribution system.

Recorded number of customers' served on each of the distribution system.

Recorded number of customers' interruption on each of the distribution system

\subsection{Method used}

Statistical analysis was adopted to determine the mean and Standard

Deviation of the system reliability indices: SAIDI, SAIFI and CAIDI. 
(i) The system reliability indices - SAIDI, SAIFI and CAIDI were computed.

(a) System Average Interruption Duration Index, SAIDI is given by;

$$
\text { SAIDI }=\frac{\text { Customerint erruptiondurations }}{\text { Total Number of Customers Served }}
$$

$$
=\frac{\sum_{i=1}^{n} r_{i} N_{i}}{\sum_{i=1}^{n} N_{T}}
$$

(b) System Average Interruption Frequency Index, SAIFI is given by

$$
\begin{aligned}
& \text { SAIFI }=\frac{\text { Total number of customer int erruptions }}{\text { Total Number of Customers Served }} \\
= & \frac{\sum_{i=1}^{n} N_{i}}{\sum_{i=1}^{n} N_{T}}
\end{aligned}
$$

(c) Customer Average Interruption Duration Index, CAIDI is given by

$$
\begin{aligned}
& \text { CAIDI }=\frac{\text { Customer int erruption durations }}{\text { Total Number of Customers Interrupti on }} . \\
& =\frac{\sum_{i=1}^{n} r_{i} N_{i}}{\sum_{i=1}^{n} N_{i}}
\end{aligned}
$$

The mean value $\mu \mathrm{x}$ of a set of $\mathrm{N}$ measured values for the random variables $\mathrm{X}$ is obtained by summing the values and dividing by $\mathrm{N}$.

$$
\mu_{X}=\frac{\sum_{i-1}^{N} X_{i}}{N}
$$

Expected value:

The expected value $\mathrm{E}[\mathrm{X}]$ of the random variable is the mean value obtained if all Possible values of the random variables were multiplied by their likelihood of occurrence and summed. The mean and expected value are numerically the same.

$$
\begin{aligned}
& E[X]=\mu_{x} \\
& =\int X f(x) d x \\
& \quad=\sum X_{P}\left(X_{i}\right)
\end{aligned}
$$

Where:

\section{Variance:}

$$
\begin{aligned}
& \mathrm{f}(\mathrm{x})=\text { probability density function of } \mathrm{X} \\
& \mathrm{P}(\mathrm{X} i)=\text { probability density function of } \mathrm{Xi}
\end{aligned}
$$

The variance $\operatorname{Var}[\mathrm{X}]$ of a random variable $\mathrm{X}$ is the expected value of the squared difference between the random and its mean value.

$$
\begin{aligned}
\operatorname{Var}[X]=E\left[\left(X-\mu_{x}\right)^{2}\right] & \\
= & \int\left(X-\mu_{x}\right)^{2} f(x) d x \\
= & \frac{\sum\left[\left(X_{i}-\mu_{x}\right)^{2}\right]}{N}
\end{aligned}
$$




\section{Standard deviation:}

To express the scatter or dispersion of a random variable about its expected value in the same unit as the random variable itself, the standard deviation $\sigma \mathrm{x}$ was taken as the square root of the variance. Thus:

$$
\sigma_{x}=\sqrt{\operatorname{Var}[X]}
$$

\subsection{Discussion of Results}

\subsection{Case Study 1: Kaduna Distribution System.}

The mean and standard deviation for SAIDI, SAIFI and CAIDI for Kaduna distribution system is shown in Figures 1 to 6.FDR 3 feeder of Kaduna distribution system had the highest mean SAIDI of 0.1064, with a standard deviation of 0.0516 and a SAIDI contribution of 0.0010 as shown in Figures 1 and 2..Customers connected to this distribution feeder were exposed to long time of interruption leading to complete period of darkness. Junction Road feeder recorded the least mean SAIDI of 0.0704 with a standard deviation of 0.0384 and a SAIDI contribution of 0.0010 . customers on this feeder experienced intermittent interruption.

St. Gorald feeder had the highest mean SAIFI of 0.2727, a standard deviation of 0.0958 and a SAIFI contribution of 0.0053 . This feeder also recorded the least mean CAIDI of 0.2770 , a standard deviation of 0.1968 and a CAIDI contribution of 0.0054 as shown in Figure 3.

A few proportion of the customers attached to this feeder were adequately served.

This feeder also recorded the highest mean CAIDI of 0.5706, a standard deviation of 0.3214 and a CAIDI contribution of 0.0083 . FDR 2 feeder recorded the least mean SAIFI of 0.1869 , a standard deviation of 0.0177 and a SAIFI contribution of 0.0027 because many of the customers attached to this feeder were adequately served after an appreciable reduction in the number of customers' interruption as illustrated in Figures 4 to 6 .

\subsection{Case Study 2: Kano Distribution System.}

The mean and standard deviation for Kano distribution system is shown in Figures 7 to 12.Bangauda feeder of Kano distribution system recorded the highest mean SAIDI of 0.1462 with a standard deviation of 0.0128 as well as the highest mean CAIDI of 0.6263 with a standard deviation of 0.1170 . Bangaudahad SAIDI and CAIDI contributions of 0.0031 and 0.0132 respectively. This is because the prolonged period of interruption had put the customers on this feeder in a complete darkness since the faults were not cleared.

The least mean SAIDI of 0.0497 , a standard deviation of 0.0153 and a SAIDI contribution of 0.005 were recorded on Spare feeder of this distribution system as shown in Figures 7 and 8.. This distribution feeder also recorded the least mean CAIDI of 0.2083 , a standard deviation of 0.0631 with a CAIDI contribution of 0.0020 . Many customers connected to this feeder experienced a shorter period of interruptions as illustrated in Figure 9.

Spare feeder also had the highest mean SAIFI of 0.2384 , a standard deviation of 0.0144 and a SAIFI contribution of 0.0023 as shown in Figures 10 to 12. Customers on this feeder experienced frequent interruptions while only few of them were adequately served. Waterworks feeder had the least mean SAIFI of 0.1989, a standard deviation of 0.0101 and a SAIFI contribution of 0.0020 . Many of the customers attached to this feeder were adequately served.

\subsection{Conclusion}

A Comparative analysis of reliability indices of Kaduna and Kano distribution systems has been presented. FDR3 feeder of Kaduna distribution system recorded the highest mean SAIDI of 0.1064 compared to all other feeders in the selected distribution system. Customers on this feeder were interrupted for a prolonged time while fewer of the customers were adequately served. Junction Road feeder of Kaduna distribution system had the least mean SAIDI of 0.0704 because customers' interruption was for a short period of time even though; more customers were being served by the feeder.

Bangauda feeder of Kano distribution system recorded the highest mean SAIDI of 0.1462. More customers were interrupted compared to all other feeders on the distribution system while fewer of them were served adequately served while Spare feeder had a least mean SAIDI of 0.0497 because fewer of the customers attached to this feeder were interrupted while many of them were adequately served. 


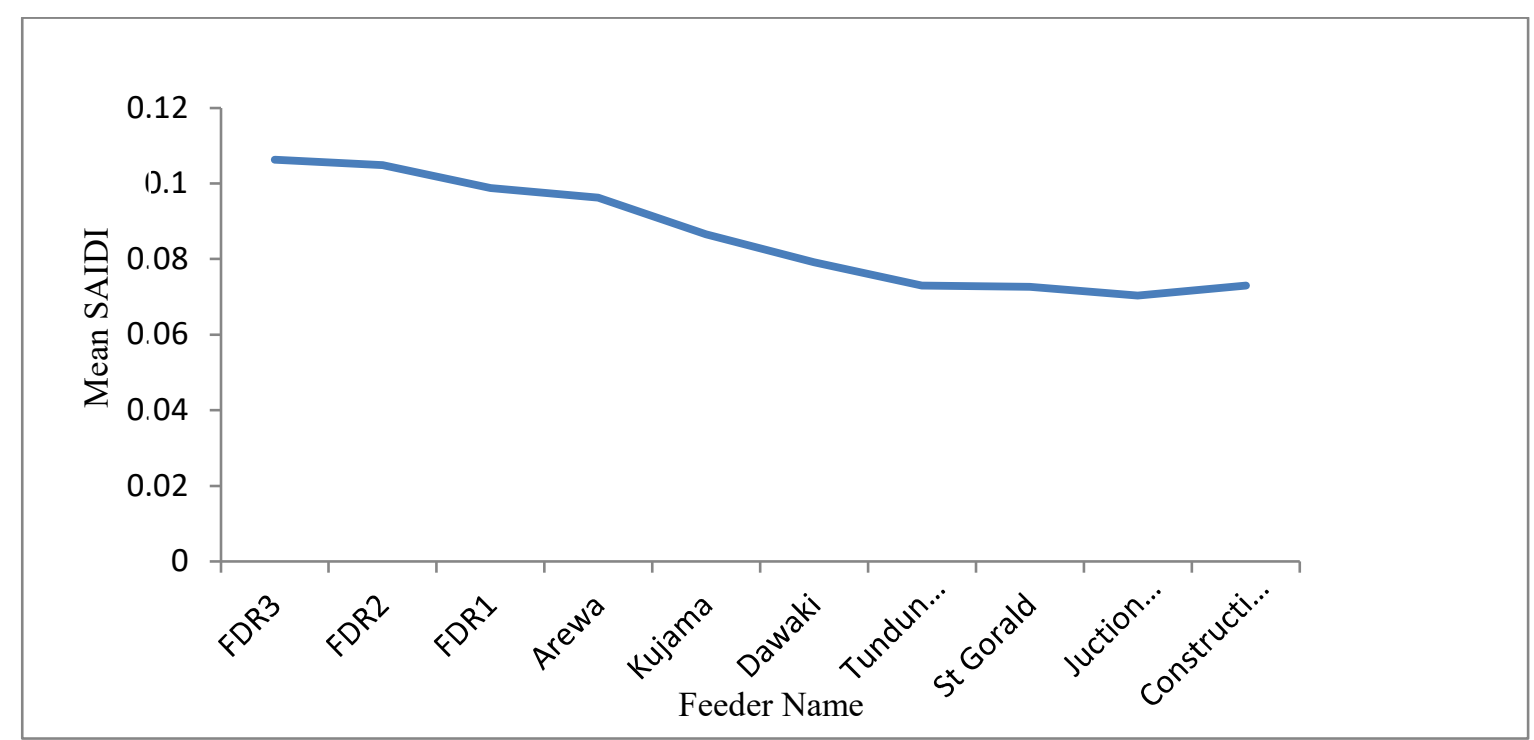

Figure 1: Mean SAIDI for Kaduna distribution systems

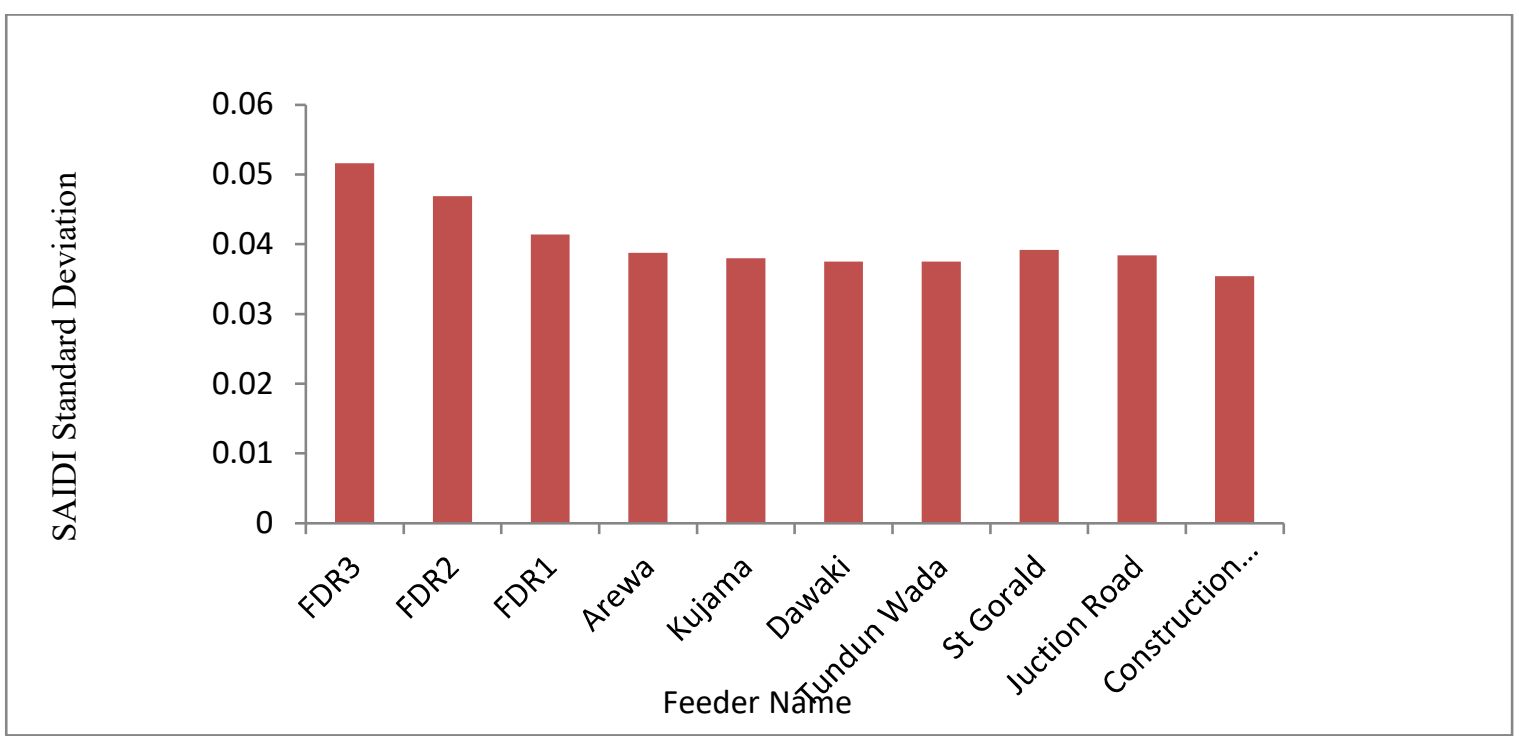

Figure 2: Standard Deviation of SAIDI for Kaduna distribution systems

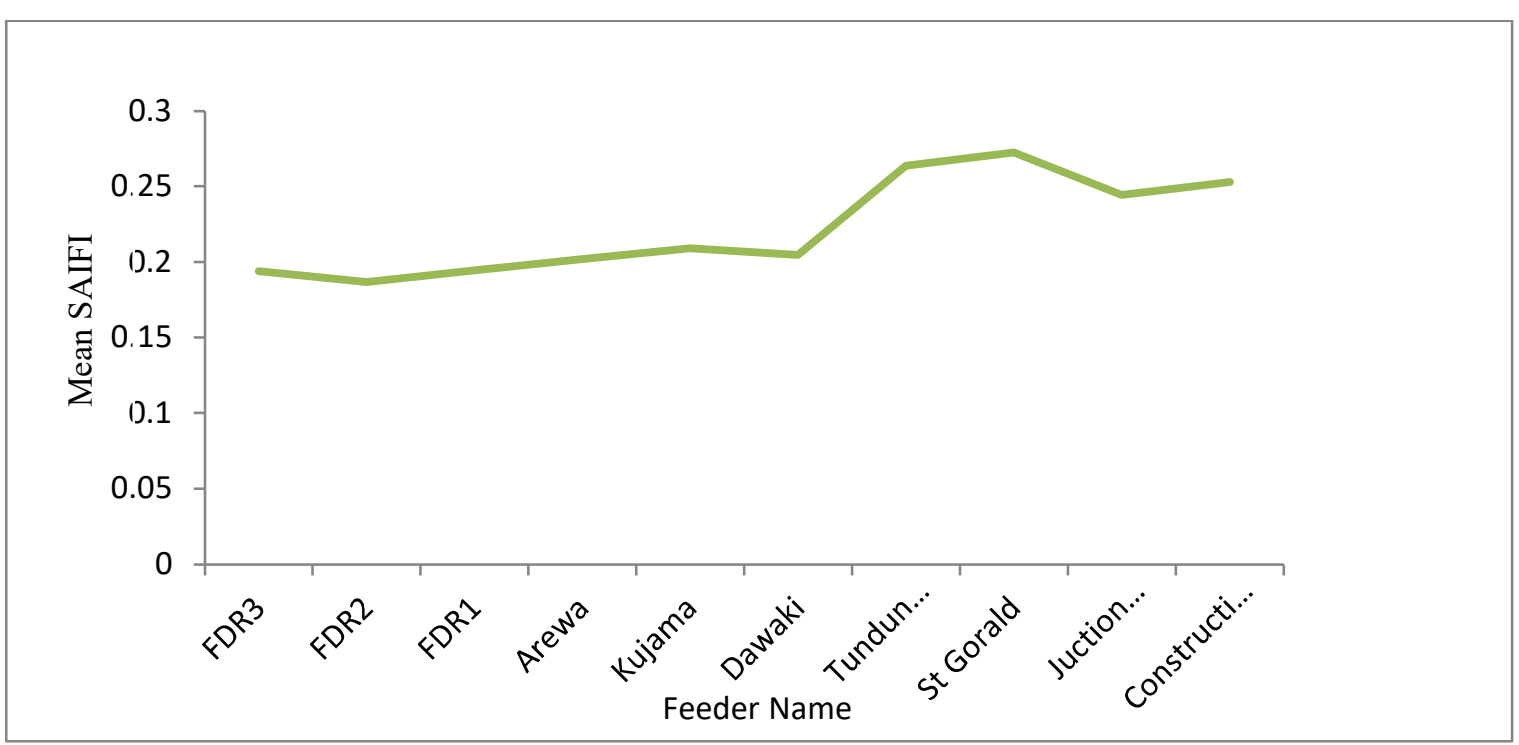

Figure 3: Mean SAIFI for Kaduna distribution systems 


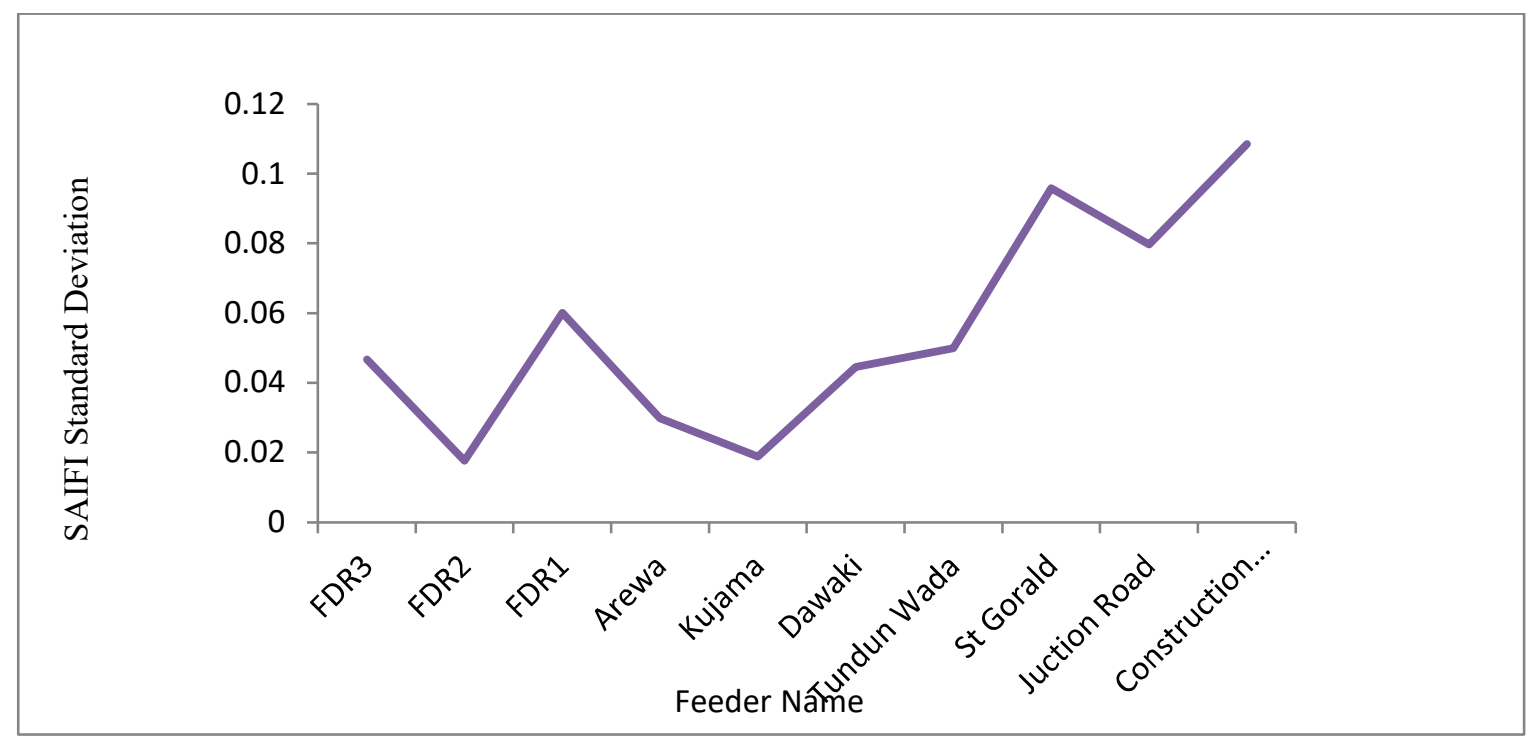

Figure 4: Standard Deviation of SAIFI for Kaduna distribution systems

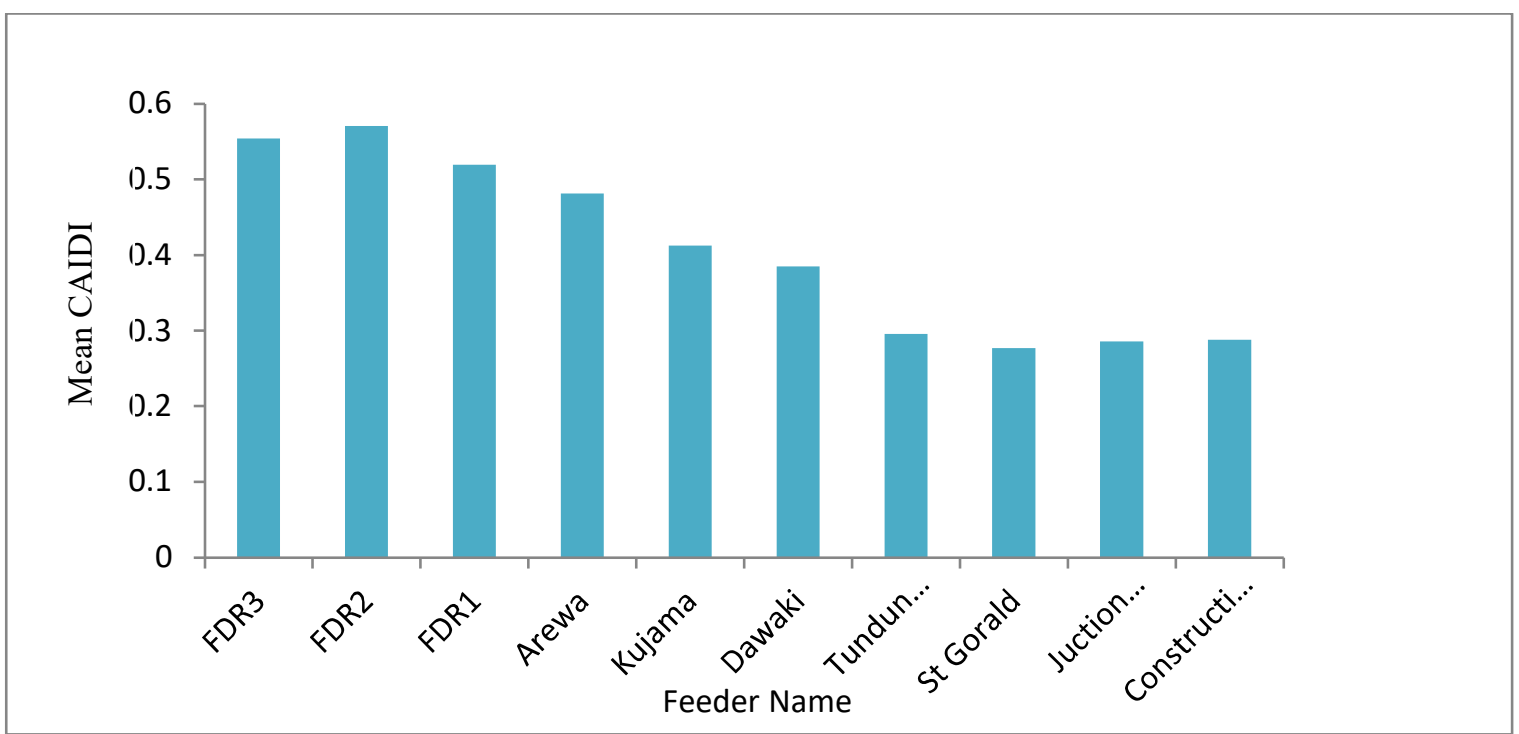

Figure 5: Mean CAIDI for Kaduna distribution systems

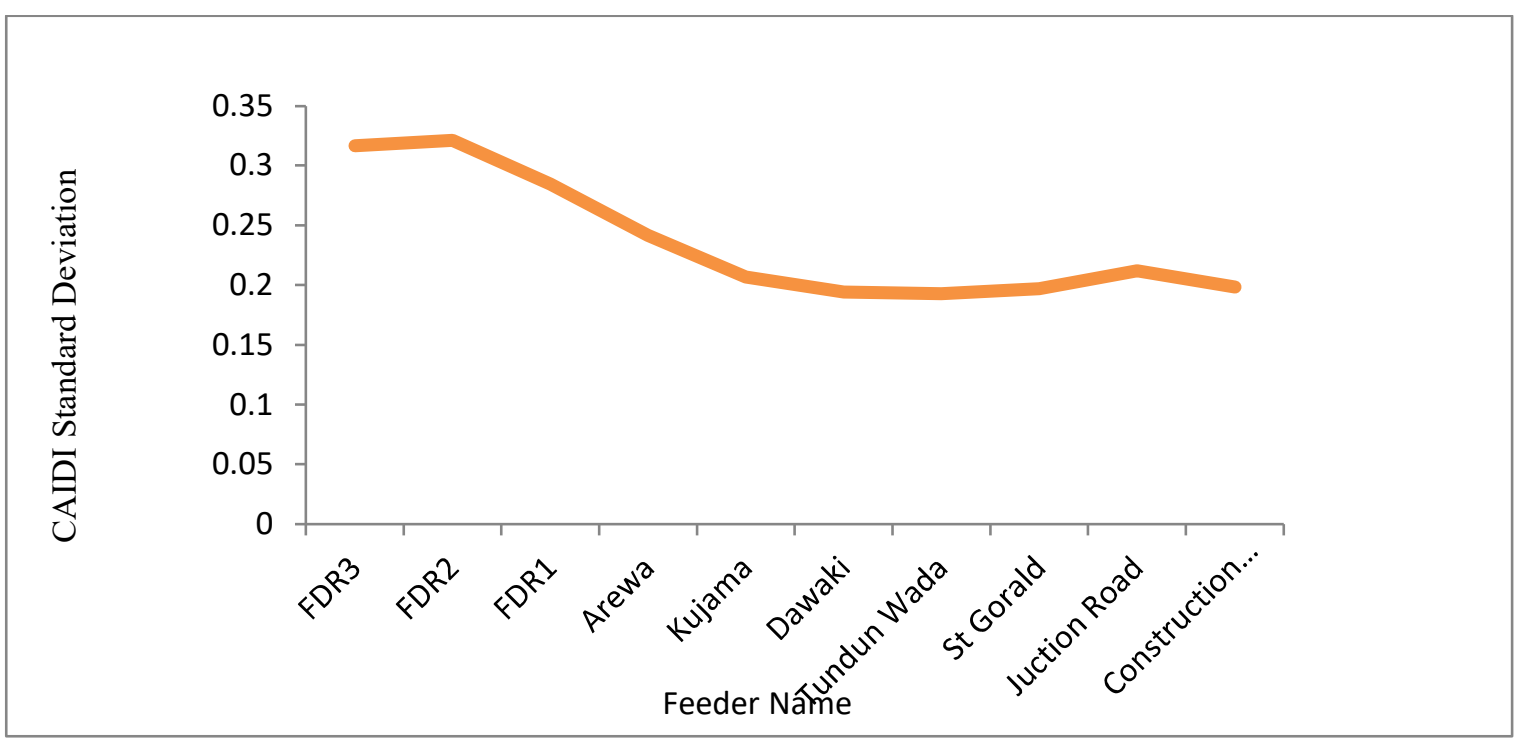

Figure 6: Standard Deviation of CAIDI for Kaduna distribution systems 


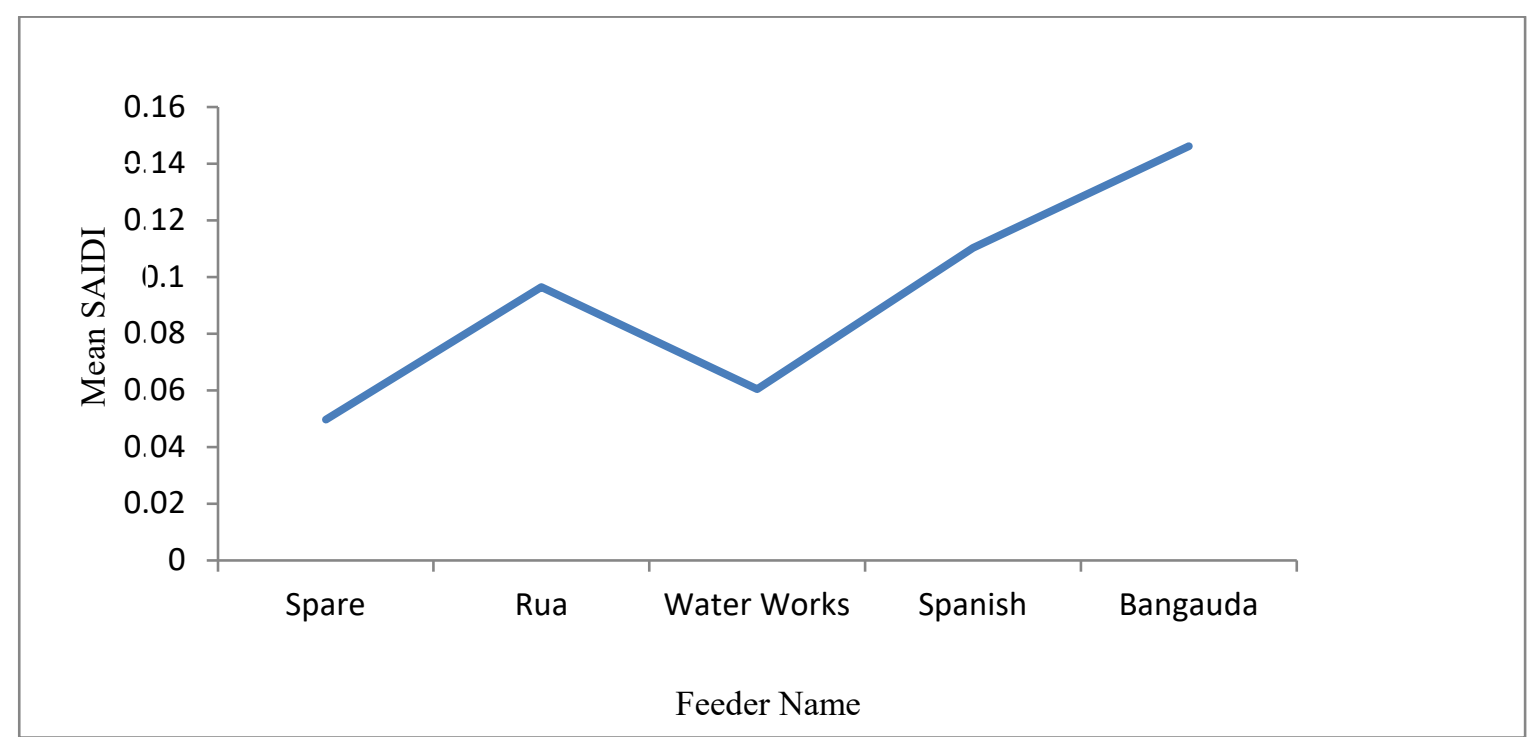

Figure 7: Mean SAIDI for Kano distribution systems

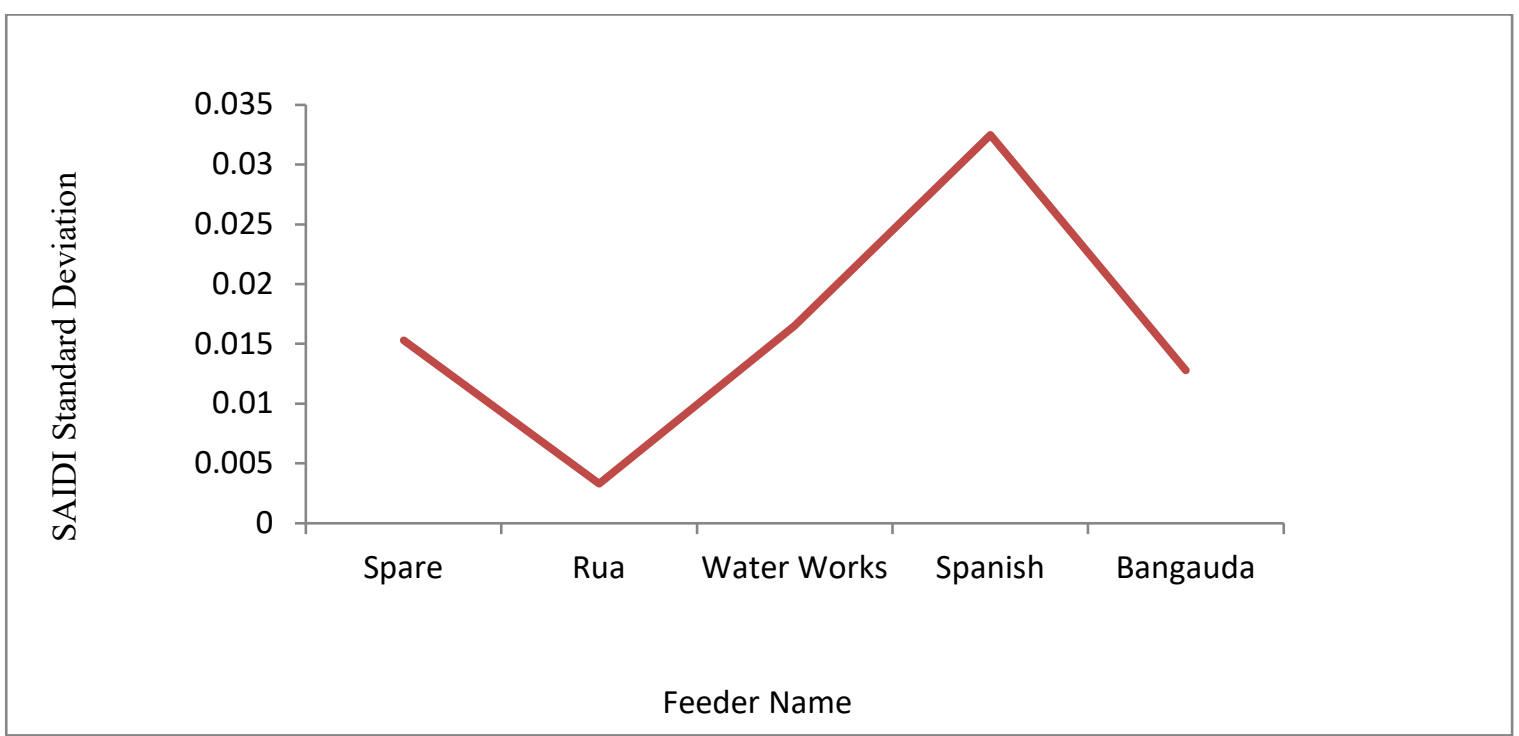

Figure 8: Standard Deviation of SAIDI for Kano distribution systems

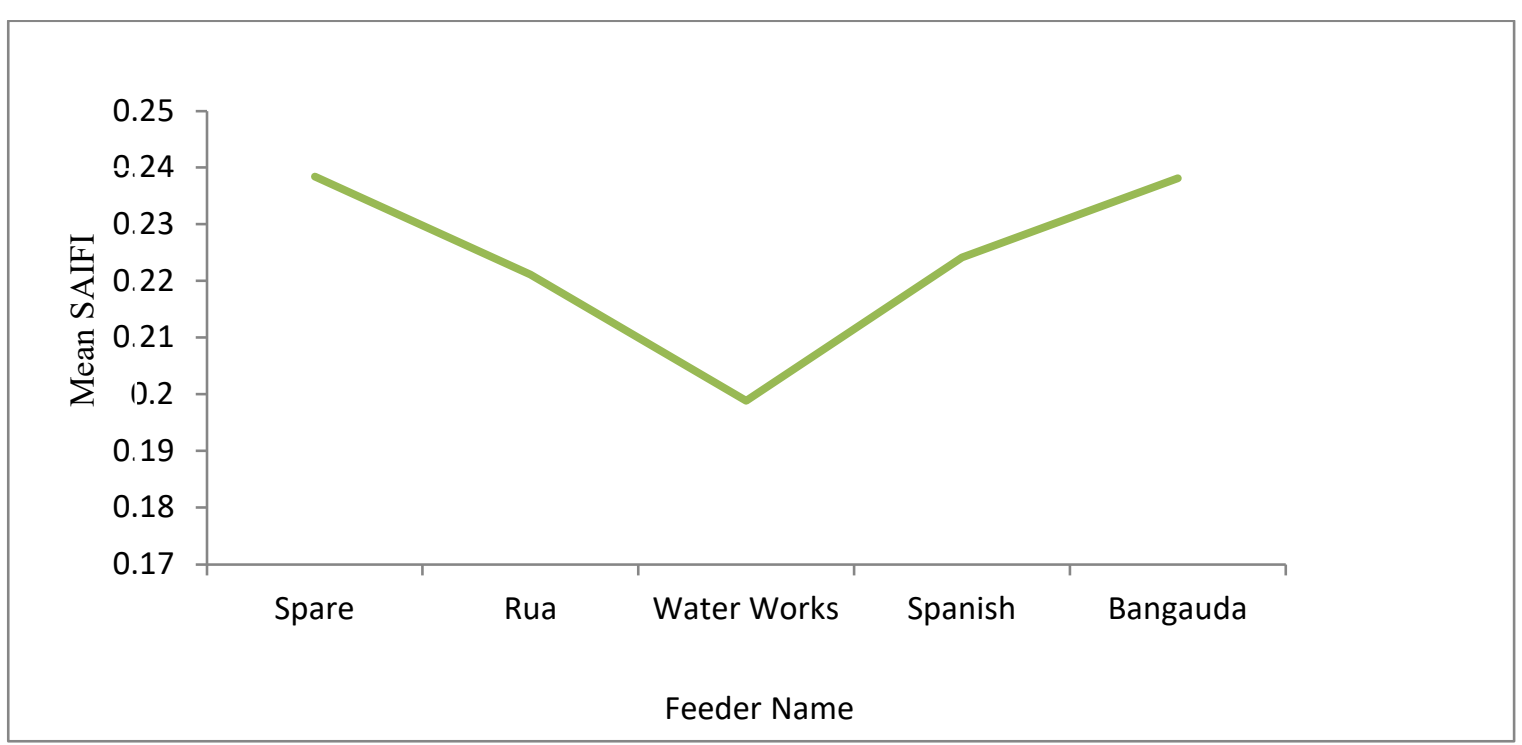

Figure 9: Mean SAIFI for Kano distribution systems 


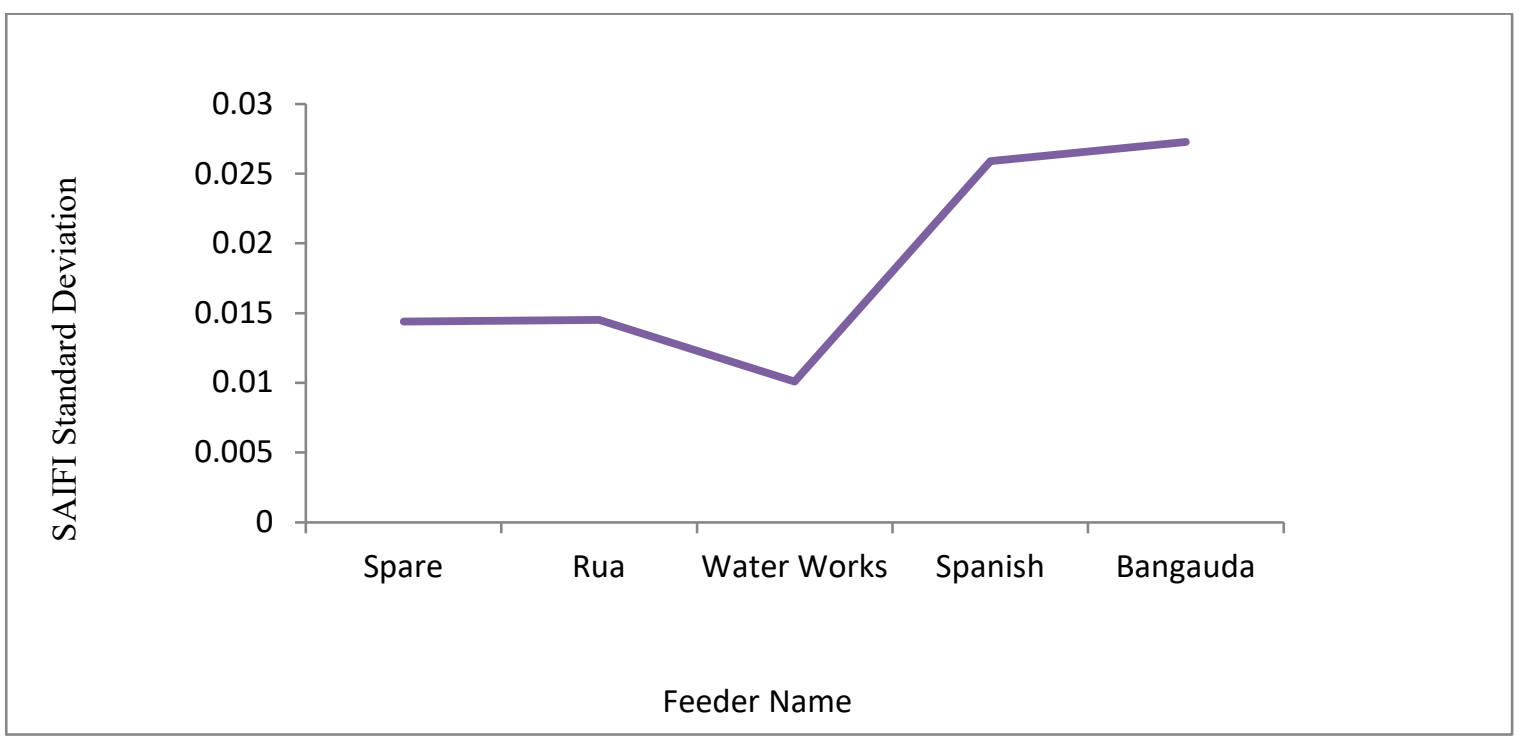

Figure 10: Standard Deviation of SAIFI for Kano distribution systems

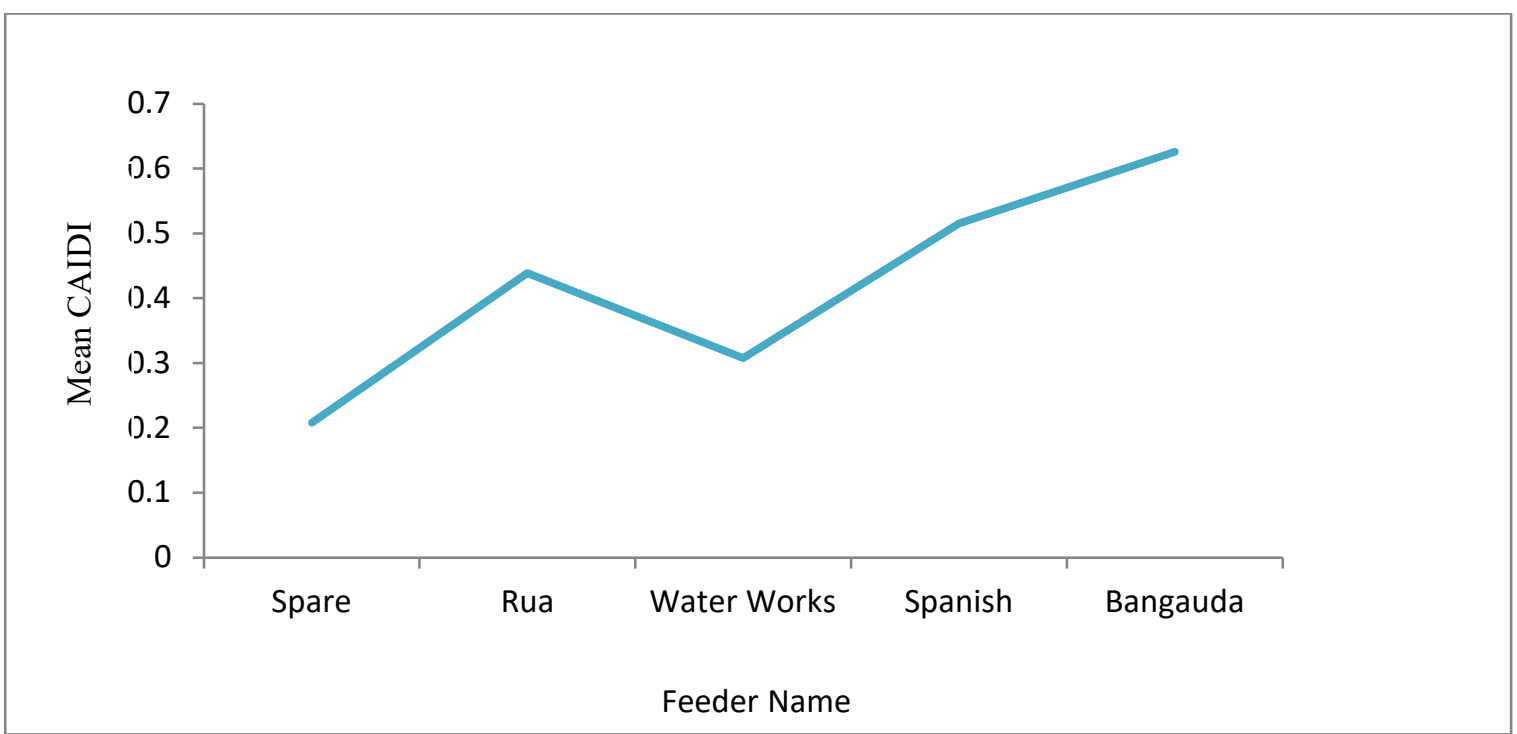

Figure 11: Mean CAIDI for Kano distribution systems

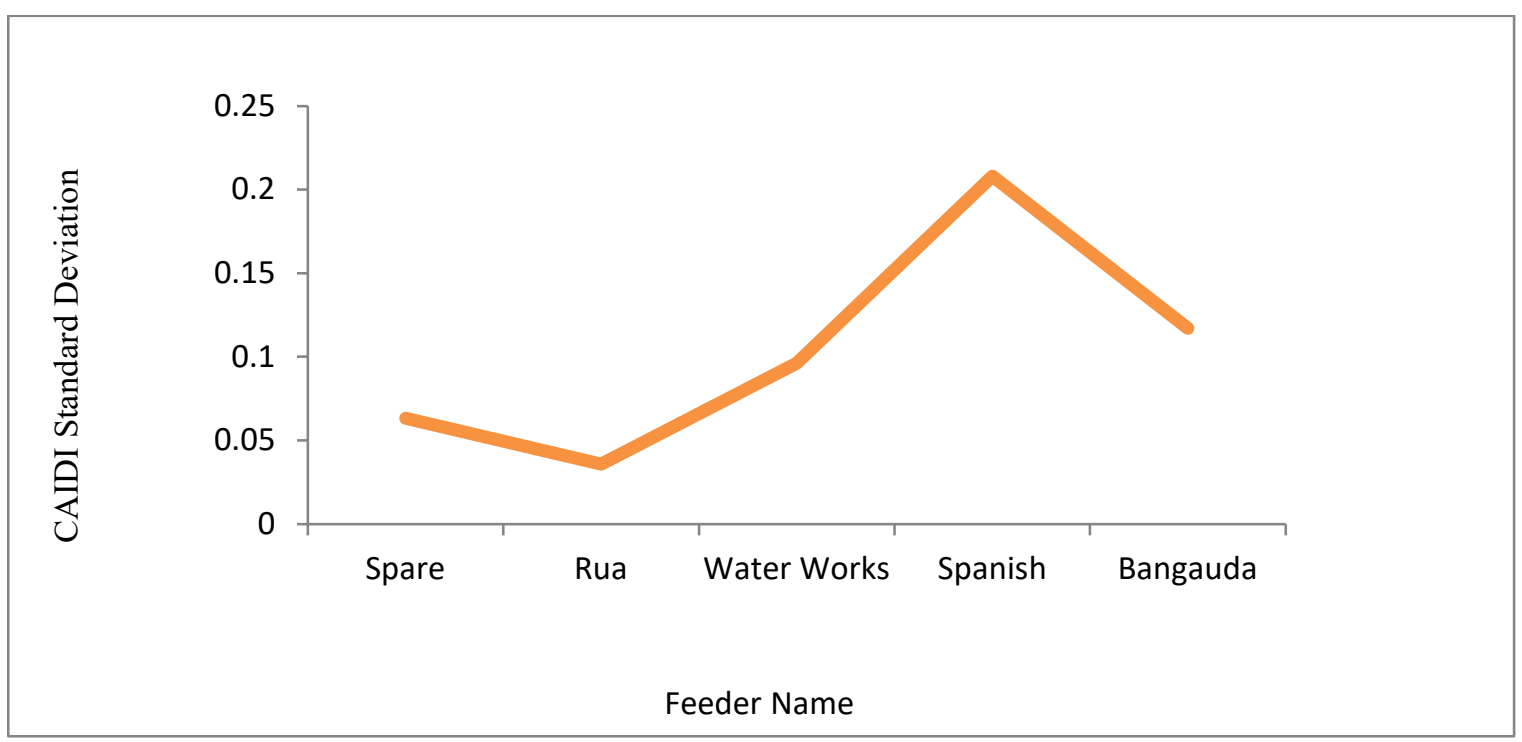

Figure 12: Standard Deviation of CAIDI for Kano distribution systems 


\subsection{References.}

Arild H and Arne T.H (2006): "Reliability modeling of gas and electric power distribution systems; similarities and differences;", 9th International Conference on Probabilistic Methods Applied to Power Systems, KTH, Stockholm, Sweden. Pp. 327-341.

Awosope, C. O. A. (1984): "Power system reliability measurement and effects of its cost-benefit aspects on society". The Nigerian Engineer Vol. 19, No. 1, 1984. pp 1-4.

Billinton R (2014): “A basic framework for generating systems operating Health analysis". IEEE Transactions on Power systems Vol. 9, No.3, pp 1610-1617

Billinton, R. and Singh, C. (2004): "System load Representation in Generating Capacity Reliability Studies". The Nigerian Engineer, Vol. 19, No 1. Page 14-19.

Billinton R and Wang P (2016): "Distribution system reliability cost/Worth Analysis using analytical and sequential simulation techniques, IEEE Transactions on power systems, Vol. 13, No. 4, pp. 1245-1250.

Danny D. (2015): "Unification of reliability/Availability/reparability models for Markov systems". IEEE Transaction on reliability. Vol. 38, No. 2, pp 246-253.

El-Kady M. A, Alaskar B. A, Shaalan A. M, and Al-Shammri B.M (2007): "Composite reliability and quality assessment of interconnected power systems”. IEEE Transactions on Power Systems, Vol. 11, No. 5, pp 328396.

Enrico C and Gianfranco C. (2004): "Evaluation of the probability density functions of distribution system reliability indices with a characteristic function-based approach". IEEE Transaction on power systems Vol. 19, No.2. pp 724-734

Farag A. S, Shwehdi M. H, Belhadj C. A, Beshir M. J, and Cheng T. C (2008): “Application of new reliability assessment framework and value-based reliability planning”. IEEE Transactions on Reliability. Vol. 18, No.3, pp 53-98

Khan M. E (2008): "Bulk load points reliability evaluation using security based model". "IEEE Transactions on power systems", Vol. 13, No. 2, pp $456-463$.

Khan E and Billinton R. (2012): "A Hybrid Model for Quantifying Different Operating States of Composite Power Systems”. IEEE Transactions on Power Systems, Vol. 7, No. 1 Pp 93-98.

Khodr H.M, Martinez-Crespo J, Matos M. A and Pereira J. (2017): "Distribution Systems reconfiguration based on OPF using Benders decomposition", IEEE Transactions on power delivery, Vol. 24, No. 4, pp. 2166-2176.

Mahmud F and Saeed A (2009): "Reliability analysis in electrical distribution system considering preventive maintenance applications on circuit breakers", World Academy of Science, Energy and Technology, Vol. 3, No. 4, Pp. 741-752.

Meysam J and Hasan M (2009): "Scheduling of spinning reserve considering customer choice on reliability", IEEE transactions on power system, Vol. 24, No. 4,Pp 1780-1789.

Mitra J and Singh C. (2006): Incorporating the D.C load flow model in the Decomposition simulation method of Multi Area reliability evaluation, IEEE Transactions on power systems, vol. 11, No. 3, pp 1245 - 1252.

Nagaraj B., Subrahmanyam S. V. and Richard D C. (2014): "Modelling and analysis of distribution reliability indices.” IEEE Transactions on power delivery, Vol. 19, No. 4, pp. 101-109.

Noferi, P.I. and Paris I. (2014): "Quantitative Evaluation of Power System Reliability in Planning Studies”. IEEE Transactions on Power Systems, vol. 7, No. 3. pp 416-438

Roberts, N.H, Andrew C. and Brown Y. (2008): "Comparative analysis of distribution reliability improvement", IEEE Transactions on power systems, Vol. 11, No. 2,pp. 69-73.

Sacket, R. K, Bansal R. C and Singh C. O. (2007): "Reliability evaluation of power system considering voltage stability and continuation power flow on power system". IEEE Transactions on Power Systems, Vol. 7, No.1, pp. $258-263$.

Sakis M. A. P. Fang Y., George J.C., and Binh D. Q. (2014): "Effects of protection systems hidden failures on bulk power system reliability", Power system Engineering research centre (PSERC), pp. 1-7

Sakis M. A.P., Carol C. S, and Feng X. (2006): "Performance Evaluation of Static Security Analysis Methods", IEEE Transactions on Power Systems, Vol. 9, No. 3, Pp. 1441-1449.

Sakis M. A.P., George C. J., Xing Y. C., (2015): A new probabilistic power analysis method”, IEEE Transactions on Power Systems, Vol. 5 No. 1, Pp. 182-190.

Singh C., J. Mitra J. (2006): “Composite System Reliability Evaluation using State space Pruning”, IEEE Transactions on Power Systems, Vol. 12, No. 1. Pp. 471-479.

Singh, C and Billinton, R. (2005): "Frequency and Duration concepts in system reliability evaluation". IEEE Transactions on Reliability, Vol. 24, No. 1. Pp. 31-36. 